\title{
Dendrobium spectabile (Blume) Miq. IN VITRO CULTURE AND ITS ACCLIMATIZATION ON MUS MEDIA WITH ANTIMICROBIAL AND ALCOHOLIC SUGAR SUPPLEMENTATION
}

\author{
Untung Santoso ${ }^{1,2 *}$, Y.Sri Wulan Manohara ${ }^{2}$, and Kusriningrum Rochiman S. ${ }^{3}$ \\ ${ }^{1}$ Faculty of Agriculture and Animal Husbandry Muhammadiyah University Malang \\ ${ }^{2}$ Biology Department, Faculty of Science and Technology, Airlangga University, Surabaya \\ ${ }^{3}$ Animal Nutrition Department of Animal Husbandry Faculty, Airlangga University, Surabaya \\ *e-mail: tungsantoso@gmail.com
}

\begin{abstract}
Germination and development of orchid seed of Dendrobium spectabile through in vitro method has been done with good result and yielded many seeds. Different acclimatization approach was developed with sphagnum moss medium which supplemented with the same nutrition as MUS medium. Alcoholic sugar was supplemented to increase medium moisture and antimicrobial was added to minimalized contamination which can harm orchid seeds. Planlet adaptation ability to drought stress which resulted from in vitro culture can be improved using the new medium. The medium will increase the probability of seed survival also it will normalize seed development through the acclimatization process.
\end{abstract}

Keywords: Orchid, in vitro, acclimatization, alcoholic sugar, antimicrobial.

\section{INTRODUCTION}

Kew Royal Botanical Garden estimated that there are about 2.380.000 plant species which endangered by human activities (Irawati, 2011). One of endanger plant group is orchidaceae. There are 44 species of orchid which categorized in conservation priority (Risna et al., 2010). Dendrobium spectabile is one of those endanger species list. This orchid has unique form appearance but has limited distribution because of its shrinking habitat. Utilization and hybridization were not explored yet which make the condition become worse. According to The International Orchid Register, D. spectabile has been hybridized for 19 times (Robinson, 2013).

Orchid seed does not have food reserve, it depends on mycorrhiza for its germination process (Sin, et al. 2002). In vitro technique will enhance orchid seed growth ability up to $90 \%$ (Doijode, 2001), but there are also some seeds with low growth ability (Arditii, 1992). In vitro orchid seed germination has been done for conservation and commercial purposes. Orchid seed germination success was reported on Dendrobium tosaense (Lo et al., 2004), Aerides multiflorum, A. odorata, Dendrobium supperbum, Doritis pulcherima, Vanda densisoniana (Luan et al., 2006), Aplectrum hyemale (Lauzer et al., 2007), Grammatophyllum speciosum, Bulbophyllum vaginatum, Bulbophyllum membranaceum, Cymbidium finlaysonianum and Cymbidium bicolor (Yam et al., 2010).

Orchid cultivation by in vitro method requires adaptation process of seed from bottle external environment which called ex vitro after being in vitro cultivated. The process of seed adaptation to external environment is called acclimatization (Brian and Rittershausen, 2003). According to Hazarika (2003) acclimatization process of plant seed is affected by plant variant, plantlet age, culture medium, micro environments (humidity, light intensity, temperature), microorganism, also nutrients. Santoso (2007) explained that operator factor and acclimatization methods often affected on the success of acclimatization process.

This study approach is minimizing the difference of micro environmental between in vitro and ex vitro medium on acclimatization process. This study aims to identify in vitro seed germination process which cultured in asymbiotic with Dendrobium spectabile on MUS medium, also find out the effect of MUS medium nutrients which supplemented with alcoholic sugar and antimicrobial on acclimatization of orchid seeds.

\section{METHODS}

D. spectabile ripe fruits were obtained from Nursery Anggrek Agro Muhammadiyah University Malang. This fruit was yielded from selfing (mating of pollen and stigma from the same flower) of D. spectabile parental Biak Island, Papua origin. Orchid ripe fruit were sterilized using $90 \%$ of alcohol then put on the MUS medium which done in the laminar air flow. All the equipments such as medium bottle, long tweezers, scalpel, scissor, Bunsen, alcohol $70 \%$, and petri dish have been sterilized. Fruits were then sunk into alcohol $70 \%$ and burned until the flame dead. Seed were taken out from fruit using long tweezers then spread into MUS medium in bottle.

MUS medium which used in this study was composed by $200 \mathrm{mg}$ of tricalsium phospate $\left(\mathrm{Ca}_{3}\left(\mathrm{PO}_{4}\right)_{2}\right), 525 \mathrm{mg}$ of potassium nitrate $\left(\mathrm{KNO}_{3}\right), 250 \mathrm{mg}$ of monopotassium phospate $\left(\mathrm{KH}_{3} \mathrm{PO}_{4}\right), 500 \mathrm{mg}$ of ammonium sulphate $\left(\left(\mathrm{NH}_{4}\right) \mathrm{SO}_{4}\right), 28 \mathrm{mg}$ of feric tartrate $\left(\mathrm{Fe}_{2}\left(\mathrm{C}_{6} \mathrm{H}_{4} \mathrm{O}_{6}\right)_{3}\right), 250 \mathrm{mg}$ of magnesium sulphate $\left(\mathrm{MgSO}_{4} .7 \mathrm{H}_{2} \mathrm{O}\right), 7.5 \mathrm{mg}$ of mangane sulphate $\left(\mathrm{MnSO}_{4} \cdot 4 \mathrm{H}_{2} \mathrm{O}\right), 10 \mathrm{mg}$ of mio-inositol, $0.5 \mathrm{mg}$ of thiamin $\mathrm{HCl}, 0.5 \mathrm{mg}$ of pyridoxine, $0.5 \mathrm{mg}$ of niacin, $20 \mathrm{~g}$ of glucose, $10 \mathrm{~g}$ of fructose, $20 \mathrm{ml}$ of cocconut water, and 7 $\mathrm{g}$ of agar. All of the components were diluted on distillated water up to $1000 \mathrm{ml}$. Medium $\mathrm{pH}$ was adjusted to 5.6 number. 
Acclimatization steps through ex vitro were analyzed using factorial randomized block design with 2 factors and 3 replications. Medium used was moss sphagnum with MUS medium nutrients and alcoholic sugar supplementation (factor 1: medium without alcoholic sugar supplementation, ethylene glycol, xylitol, and sorbitol) and antimicrobial (factor 2: without antimicrobial, diethyl pyrocarbonate, ethyl parabene, benzoic acid, and potassium sorbate). MUS nutrient addition with alcoholic sugar and antimicrobial were done every 3 days for 3 months of acclimatization. Percentage of orchid life seed, leaf amount, fresh weight, morphology of leaf, root, and stem (bulb) were recorded.

\section{RESULTS}

\section{D. spectabile seed germination on MUS medium}

Selected $D$. spectabile can be bred by selfing or mating of pollen and stigma from the same flower. All of nine flowers have been successfully formed fruit, within 2 weeks bred results can be evaluated from their green bulging receptacles. When breeding failed, the receptacles will turn yellow and fall off. Corolla of flowers which formed fruit will stay at the end of fruit, its color will going deeper and its size is getting bigger.

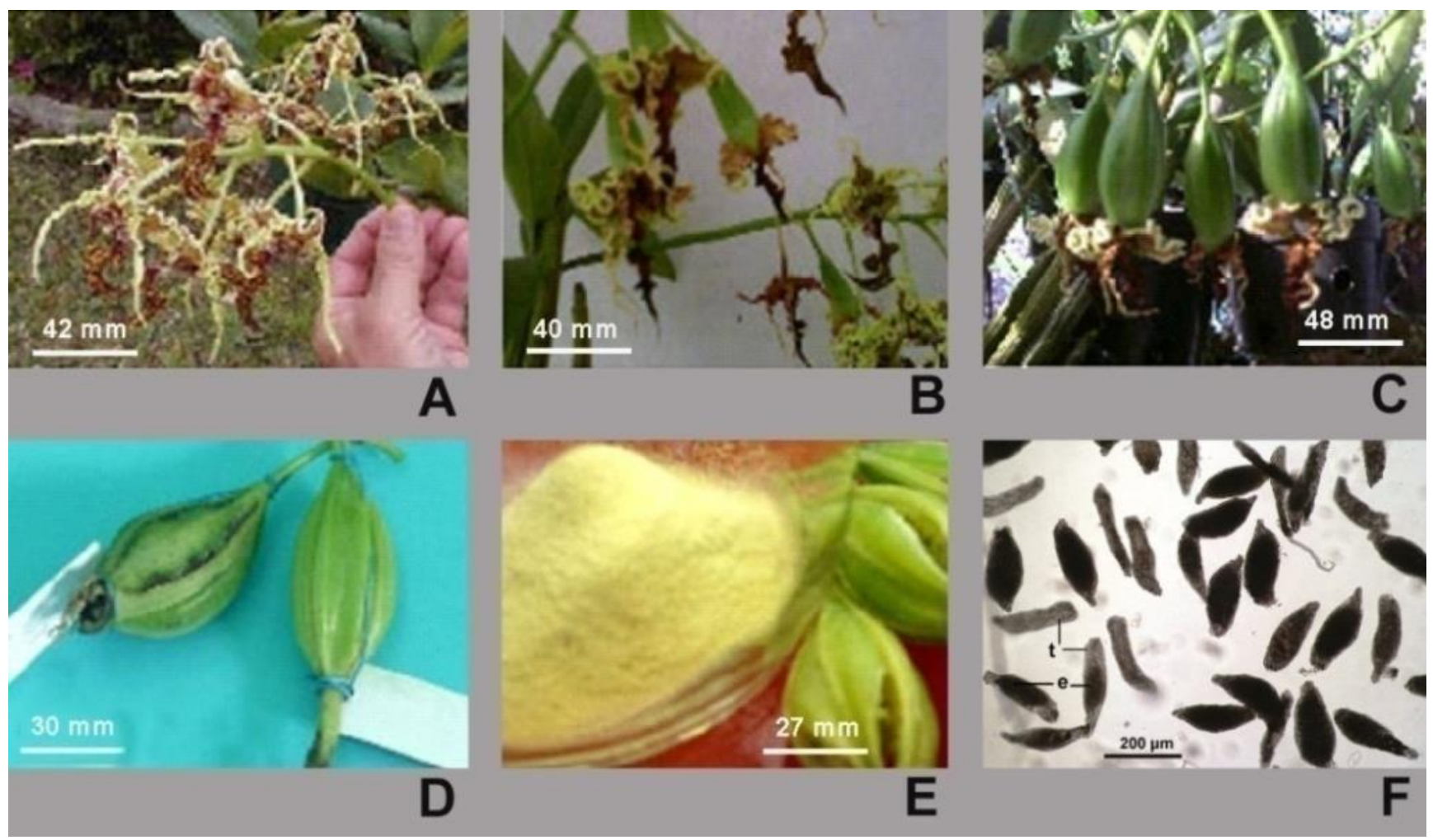

Figure 1. Selfing process and handle method. Flower which being bred (A). Successfully bred flower (B). Eight months old of D. spectabile fruit (C) Harvested fruit at the exact time (D). Orchid seed obtained from fully ripe and broken fruit (E). Orchid seed microscopic appearance (F). Embryo (e). Veil or testa $(\mathrm{t})$.

Fruit maturation of $D$. spectabile took long time, it was 256 days (almost 9 months). Fruit maturity can be identified from its protruding bulkhead which turned yellow. Fruit texture become supple and will broke when get touched (Figure 1).

Harvested seed was then germinated on MUS medium. Germination process of $D$. spectabile seed took time up to 5 months which characterized by seed color changing from yellowish white into light green with soft surface. Its soft surface will become rougher by the time because seed has formed protocorm.

General description of seed development is presented on Figure 2A. Orchid seed was spread on MUS medium aseptically in LAF (Laminar Air Flow). Five months germination process was shown on Figure 2A (a-b). First germinated seed then sub-cultured multiple times. Firs subculture which moved to be grown is seed which already formed protocorm. The protocorm was grown for 3 months which will form primordial of leaf and root. Protocorm population which found in each culture bottle was thousands (Figure 2A: b-c). Sub-cultured protocorm then re-sub-cultured aseptically for thinning process. Thinning will increase the growth probability of protocorms which can have root, stem, and leaf. Protocorm population which found in each culture bottle were become hundreds and left for 3 months (Figure 2A: c-d). The second sub-culture then 
re-sub-cultured for final sub-culture with smaller population, it was 30 plantlets of each culture bottles. Final

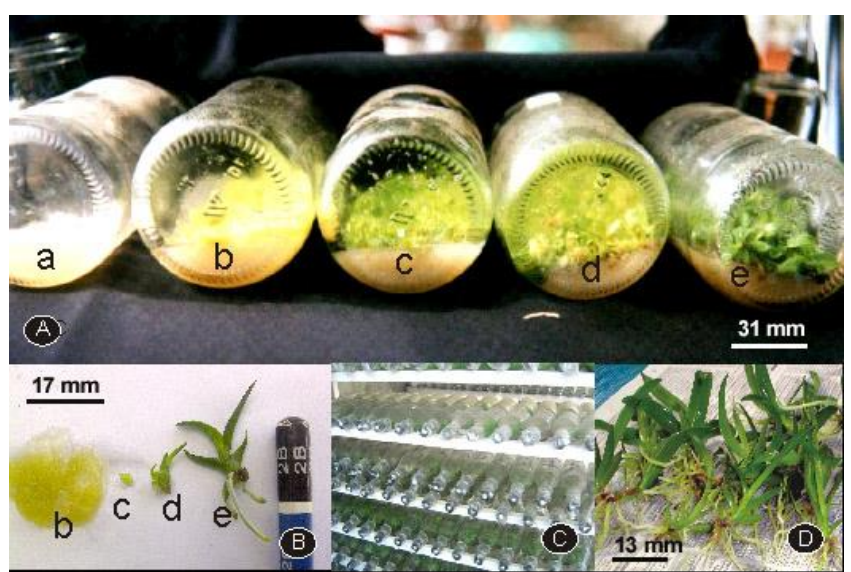

Figure 2. Culture steps of D. spectabile seed (A) from seed spreading (a) until final sub-culture (e). Seed development (B) from seed (b), early sprout (c), protocorm (d), plantlet with primordial root and leaf (e), and final sub cultured plantlet with complete root and leaf (f). Different ages of seed stocks (C). Orchid seed which newly taken out from culture bottle (D).

Orchid seed development steps were clearly shown on Figure 2B. Early germinated orchid seed shown on Figure 2B-b, protocorm was Figure 2B-c, protocorm which already formed primordial root and leaf was shown on Figure 2B-d, and completely formed root, stem, and leaf plantlet shown on Figure 2B-e. Figure 2C shown D. spectabile stocks, and on Figure 2D shown the orchid seed which ready to be planted.

\section{D. spectabile seed acclimatization on MUS medium with alcoholic sugar and antimicrobial supplementation Life orchid seed percentage}

Spagnum growth medium which contain MUS medium 1998 nutrients and supplemented with alcoholic sugar and antimicrobial has been proved can be used as acclimatization medium of $D$. spectabile. This condition was shown on high life orchid seed percentage which measured on acclimatization process. The lowest life seed percentage $(36.6 \%)$ was on seed which cultured on MUS medium 1998 without alcoholic sugar and antimicrobial supplementation (G0-A0). Percentage of life seed which cultured on MUS medium 1998 with alcoholic sugar and antimicrobial supplementation were high, it were about $88.9-100 \%$. Orchid seed with $88.9 \%$ life seed percentage was cultured on MUS medium without antimicrobial supplementation and ethylene glycol addition (G1-A0). This percentage also found on orchid seed which cultured on MUS medium without antimicrobial supplementation and xylitol addition (G2-A0) (Figure 3).

There are no deadly contamination on all of orchid seed which grown on medium with antimicrobial and alcoholic sugar supplementation. This condition was related to sorbitol is better than another alcoholic sugar in sub-cultures are ready to be acclimatized (Figure 2A: d-e).

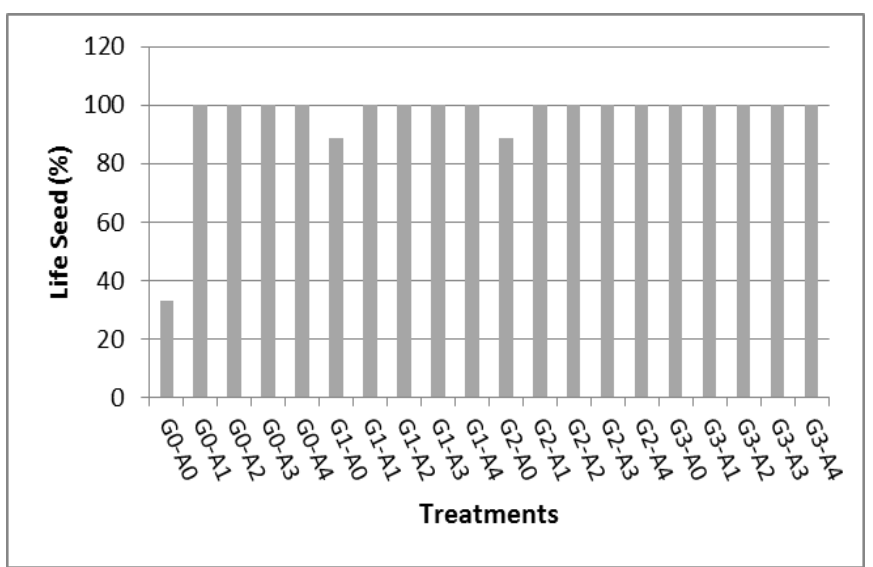

Figure 3. Orchid life seed percentage of treatment combination on MUS medium supplemented with alcoholic sugar and antimicrobial up to 16 weeks after plantation (WAP). G0 = without alcoholic sugar, G1 = ethylene glycol, G3 = sorbitol, A0 = without antimicrobial, A1 = diethylpyrocarbonate, $\mathrm{A} 2=$ ethyl parabene, $\mathrm{A} 3=$ benzoic acid, and $\mathrm{A} 4=$ potassium sorbate.

maintaining micro-environment condition of growth medium. Plant seeds will be survived from deadly contamination.

\section{Plant morphology}

Alcoholic sugar and antimicrobial supplementation affect on orchid morphology in similar pattern. Orchids which used in this study were young with morphological change tendency depend on growth factor. Leaf morphology observation shown that leaf shape is lancet with leaf long similar to 3 times of leaf width. The interesting thing from its leaf morphology is morphological change tendency. When orchid were moved to ex vitro environment with MUS nutrition, its leaf became shorter and wider (Figure 4, left).

Leaf color of orchid which already moved into ex vitro environment were relative greener than plantlets leaf. Cultured orchid bulbs were not bulging, it was lengthen and slender, otherwise orchid bulbs which grown in ex vitro environment were bulging. Bulb condition were similar in all of treatment combinations, its shape were tend to be bulging, segmented, and leaf are tend to be located on terminal with 2-3 leaf sheets in each bulb.

Visually, root morphology was different significantly on treatment combinations of alcoholic sugar and antimicrobial supplementation compared to control. Root size on control was on optimal size compared to other treatment combinations. Generally, alcoholic sugar and antimicrobial supplementation were not affected on root morphology. D. spectabile root type was fiber, it had no branches when it was on early developmental stage. The branches were formed when it start to budding. These 
conditions have shown that root development was better than leaf development.

\section{Number of Leaf}

Analysis of variance result shown that alcoholic sugar and antimicrobial treatments were affected on number of leaf. Significant different test on all age of observation (6,
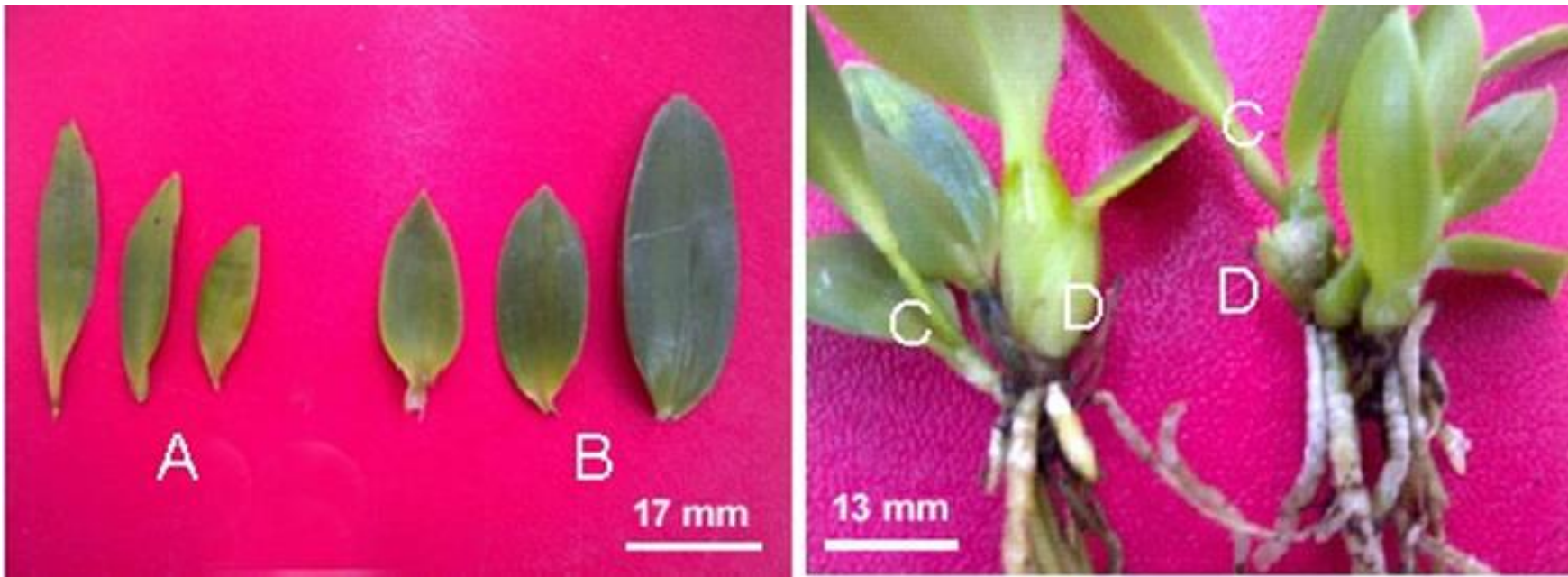

Figure 4. Leaf, stem, and root morphology on $15 \mathrm{~g} / \mathrm{l}$ of sorbitol and $2.5 \mathrm{~g} / \mathrm{l}$ of ethyl parabene. Planlet old leaves (A), new leaves (B), old bulb with slim tendency (C), and new bulb which grown during acclimatization (D). White lines show each picture bar.

\section{Fresh weight}

Fresh weight parameter was measured on 16 weeks of plantation. Analysis of variance showed that there is no significant effect of interaction between alcoholic sugar and antimicrobial supplementation on orchid fresh weight. The highest fresh weight was yielded from orchid which treated with alcoholic sugar were sorbitol (G3) and xylitol (G2), while which treated with antimicrobial was ethyl paraben (A2). Fresh weight mean of orchid which treated with alcoholic sugar and antimicrobial supplementation were presented on Figure 5.

\section{DISCUSSION}

Germination process of D. spectabile seed asymbiotically on in vitro method has yielded many orchid seeds. One of fully ripe orchid fruit can be seeded into about 10 culture bottles. Germinated seeds then can be sub cultured into another 10 culture bottles (each 1 culture bottles would obtain about 100 subcultures). Each bottle of subcultures then re-subcultured into about 10 culture bottles (second subcultures would obtain about 1000 subcultures). For the last, the third subcultures from each second subcultures were re-subcultured into $5-7$ culture bottles with 30 similar size plants on each bottles (the final subcultures obtained about 5000 - 7000 culture bottles) (Figure 2C). It means that in each orchid fruit germination would obtained about $150.000-210.000$ plant seeds. Abundant orchid seed yielded from asymbiotic in vitro method was also reported by Dutra et al., (2008).
$8,10,12,14$, and 16 weeks after plantation) shown that orchid which planted on medium without alcoholic sugar and antimicrobial supplementation $(\mathrm{GOA} 0)$ as control was has the least number of leaf. While orchid which planted on medium with alcoholic sugar and antimicrobial were have more number of leaf without any significant differences each other.
Lo et al (2004) stated that orchid seed development was affected by medium which used for plantation. This study used MUS medium which modified from VW basic medium. MUS medium has been shown better result than VW medium (Santoso, 2010). This condition caused by nutrients and growth regulators supplementation, such as myo-inositol, 3 kinds of vitamin, fructose, and coconut water. Myo-inositol supplementation was enhanced auxin storage and distribution, filtric acid synthesis, cell wall synthesis, and stress related molecule production (Chairperson et al, 2000). While Lakitan (2011) described that vitamin is very needed by plant as growth regulator, and coconut water was mentioned by George and Sherrington (1989) as source of active compounds including hormones which related on growth rate enhancement.

Each process of seed development in becoming plantlet was normal. In vitro seed germination generally was started by shrinking of seed size, the appearance of rhizoid, and formation of primordial root with branches on the surface. Next step was the appearance 2 opposite bulges of primordial root, these bulges then developed into primordial leaf which growth and developed into orchid seed which has root, pseudobulb, and the real leaf. According to Lauzer et al (2007) on the abnormal condition, orchid seed which planted on enrichment medium could not germinate, protocorm growth was slow, had etiolase, had excessive branch structure, and had no root. 


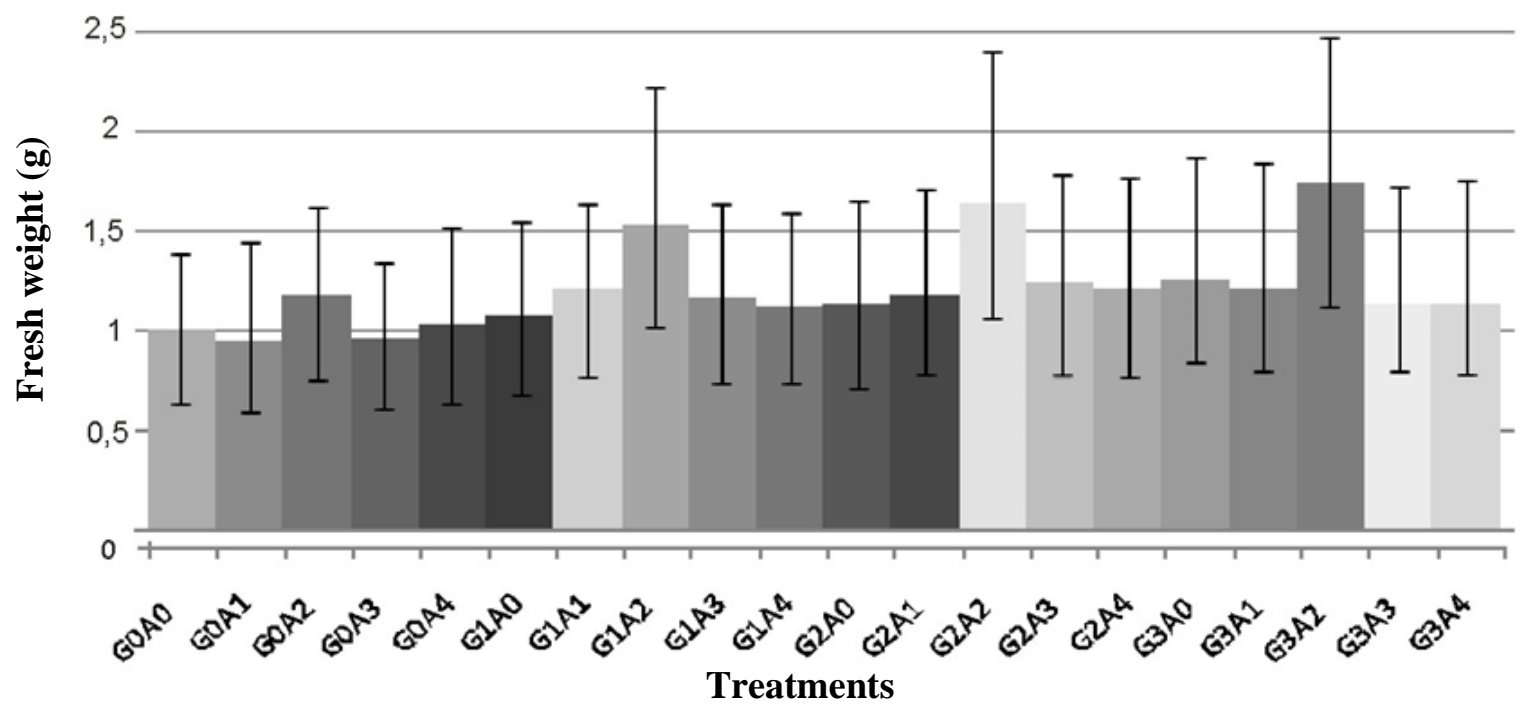

Figure 5. Orchid seed at $16 \mathrm{WAP}$ with alcoholic sugar and antimicrobial treatments (honest significant difference test $5 \%$ ). G0 $=$ without alcoholic sugar, $\mathrm{G} 1$ = ethylene glycol, $\mathrm{G} 3=$ sorbitol, $\mathrm{A} 0=$ without antimicrobial, $\mathrm{A} 1=$ diethylpyrocarbonate, $\mathrm{A} 2=$ ethyl parabene, $\mathrm{A} 3=$ benzoic acid, and $\mathrm{A}=$ potassium sorbate.

D. spectabile orchid seed yielded from in vitro method could be acclimatized as well using moss sphagnum medium which enriched with MUS and supplemented with alcoholic sugar and antimicrobial. MUS medium usage as nutrient source would make growth medium condition similar to its in vitro medium. Without alcoholic sugar and antimicrobial supplementation, orchid seed would die because of microbial contamination and water stress.

Analysis of life orchid seed percentage, number of leaf, root, stem, leaf morphology shown that alcoholic sugar and antimicrobial supplementation has an significant effect to orchid seed development, while it has no significant effect on fresh weight of seed. Generally, moss sphagnum medium usage with MUS nutrient and alcoholic sugar also antimicrobial supplementation could enhance the adaptation and growth abilities of orchid seed on acclimatization process.

According to Larcher (1995) there will be 4 reaction of plant on stress adaptation process, they are early stress reaction, defending reaction, strengthening reaction, and adaptation reaction. Orchid seed has been able to survive in the beginning of environmental change, then it was able to adapt on its new environment. The adaptations are morphological, anatomical, and physiological adaptation.

Generally, basic differentiation of orchid seed adaptation mechanism which acclimatized with MUS enrichment moss sphagnum medium and supplemented with alcoholic sugar and antimicrobial compare to control are on early and defending stage of adaptation. On the early stage of adaptation process orchid seed were more able to hold its leaf, at least only a few leaves which fell of. This mechanism allow orchid can be acclimatized on MUS medium and pass the critical time because of water limitation, nutrient, high transpiration rate, physiological change, and contamination which helped plant to survive on stressing environment. These conditions helped plants to survive and adapt on their new environment outside of culture bottle.

\section{REFERENCES}

Arditii J. 1992. Fundamental of Orchid Biology. New York: John Wiley \& Sons.

Brian and Rittershausen. W. 2003. Growing Orchid. The Complete Practical Guide to Orchid Their Cultivation. Arries Publisher Limited.

Chairperson G. E. G., Grabau E. A., and Hess J. L. 2000. Regulating Inositol Biosynthesis in Plant: Myoinositol phosphate Synthase and Myo-inositol M polytechnic onophosphate. Virginia: Faculty of Virginia Polytechnic Institute.

Doijode S. D. 2001. Seed storage of Horticultural Crops. New York: The Haworth Press.

Dutra D., Jonson T. R., Kauth P. J., Stewart. S. L., Kane M. E. and Richardson. L. 2008. Asymbiotic Seed germinating, in vitro seedling development, and greenhouse acclimatization of the threatened terrestrial orchid Bleitia purpurea. Plant Cell, Tissue, Organ Culture $94: 11-21$.

George E. F. and Sherrington P. D. 1987. Plant Propagation by Tissue Culture. Hand Book and Directory of Comercial Laboratories. England: Exegetic Limited.

Hazarika B. N. 2003. Acclimatization of Tissue-culture Plants. India: Department of Horticulture. Assam Agricultural University.

Irawati. 2011. 2011 Bulletin: Konservasi, Sebuah Renungan. Sorong:a West Papua Orchids Show.

Lakitan B. 2011. Dasar-Dasar Fisiologi Tumbuhan. Jakarta: Rajawali Press.

Larcher W. 1995. Physiology Plant Ecology. Tokyo: Springer.

Lauzer D., Renaut S., St-Aarnaud M., and Barabe. D. 2007. In Vitro Asymbiotic Germination, Protocorm Development, and Plantlet Acclimatization Aplectrum hyemale (Muhl. Ex Willd.) Torr. (Orchidaceae). Journal of the Torrey Botanical Society 134(3): 344348.

Lo S. F., Nalawade S. M., Kuo C. L., Chen C. L., Tsay H. S. 2004. Asymbiotic Germination of Immature seeds, Plantlet Development and ex vitro Establisment of Plants of Dendrobium tosaense 
Makino- A Medicinally Important Orchid. In Vitro Cell Developmental Biology-Plant 40:528-535.

Luan V. Q., Thien N. Q., Khiem D. V., and Nhut D. T. 2006. In Vitro Germinating Capacity and Plant Recovery of Some Native and Rare Orchids. Proceedings of International Workshop on Biotecnology in Agriculture. Nong Lam University. Ho Chi Minh. Vietnam.

Risna R. A., Kusuma Y. W. C., Widyatmoko D., Hendria R., and Pribadi. D.O. 2010. Species Prioritas Untuk Konservasi Tumbuhan Indonesia. Bogor: Pusat Konservasi Tumbuhan Kebun Raya BogorLembaga Ilmu Pengetahuan Indonesia.

Robinson, D. 2013. The Royal Horticultural Society Horticultural Database. www.rhs.org.uk. Accesed October $23^{\text {rd }} 2013$.
Santoso U. 2007. Aklimatisasi Anggrek Hitam Coelogyne pandurata Di Greenhouse P3AI Sebagai Model Konservasi Ex Situ. Malang: Faperta UMM.

Santoso U. 2010. Perkecambahan Biji Anggrek Langka Dendrobium spectabile (Blume) Miq. Pada Media MUS. Malang: Puskara UMM.

Sin C. S., Wing Y. M., and Arditii J. 2002. Biology of Vanda MISS JOAQUIN. Singapor: Singapore University Press.

Yam T. W., Chua. J. and Tay. sF. 2010. Conservation of the Native Orchids Through Seedling Culture and Reintroduction - A Singapore Experience. Botanical Review 76: 263-274. 